\title{
REVERBERAÇÕES DE HIROSHIMA EM MARGUERITE DURAS: A (GEO)POLÍTICA A PARTIR DO CORPO
}

http://dx.doi.org/10.11606/issn.2237-1184.v0i31p67-85

Maurício Ayer ${ }^{\mathrm{I}}$

\section{RESUMO}

Alain Resnais e Marguerite Duras situam as narrativas de Hiroshima mon amour no exato ponto em que corpo e (geo)política se chocam. Ao fazê-lo, reúnem um conjunto de elementos que reaparecerá, total ou parcialmente, em obras de Duras: o amor fulminante; sua interrupção violenta, a provocar a dor e a loucura; neste arrebatamento lírico, a personagem e o lugar misturam-se a ponto de intercambiar um mesmo nome próprio; finalmente, o reencontro com a dor e o amor torna-se possível a partir do contato com os rastros deixadas no lugar e / ou no corpo. Neste artigo, procura-se mostrar como estes elementos reaparecem em obras como India Song (1973/1975) e Césarée (1979).

\section{ABSTRACT}

Alain Resnais and Marguerite Duras articulate the stories of Hiroshima mon amour at the exact point at which body and (geo)politics collide. In doing so, they bring together a set of elements that will reappear, totally or partially, in Duras' works: a fulminating love; its violent interruption, causing pain and madness; in this lyrical ravishing, character and place are mixed one to the other to the point of exchanging the same and only proper name; finally, a new emergence of pain and love becomes possible from the contact with the traces left in the place and/or on the body. This paper shows how these elements reappear in Duras' works such as India Song (1973/1975) and Césarée (1979).

\section{PALAVRAS-CHAVE:}

Hiroshima mon amour; corpo e lugar; corpo e política; o nome próprio.

\section{KEYWORDS}

Hiroshima mon amour; body and place; body and politics; the proper name.

I Universidade de São Paulo, São Paulo, São Paulo, Brasil. 
esde o título, Hiroshima mon amour (1959), filme escrito por Marguerite Duras e dirigido por Alain Resnais, funde duas dimensões a princípio inconciliáveis: a grande história, da qual evoca o maior evento geopolítico do século XX, e a dimensão afetiva e pessoal. Sob esse título, o filme apresenta duas histórias de amor, uma no presente, em Hiroshima, outra rememorada a partir dela, vivida nos momentos finais da ocupação nazista na comuna de Nevers, na França. Essa aproximação consuma-se na cena final em que a atriz francesa dá ao seu amante japonês a alcunha da catástrofe ("Hiroshima é o teu nome"), e ele responde atribuindo a ela o nome da cidadezinha francesa.

A complexidade do gesto, que condensa elementos como o nome e o lugar, o amor e o horror, a memória e o esquecimento, é em grande medida responsável pela perplexidade que provoca e que tem suscitado leituras desde o lançamento do filme até hoje. O topônimo Hiroshima, repetido um sem-número de vezes nas falas das duas personagens, permanece perturbador, pois, à exceção das informações apenas referidas e mostradas em fragmentos na sequência inicial, seu significado histórico não é explorado no filme. Há aí, no entanto, uma conjunção de elementos cuja configuração será retomada por Duras em inúmeras outras obras, no todo ou em parte, com deslocamentos sutis ou marcantes. Neste artigo, procuro mostrar alguns exemplos dessa tópica que perpassa toda a obra durassiana. Para isso, retomo Hiroshima com o intuito de destacar esses elementos e identificar o que mobilizam, para depois observar seu ressurgimento em outras obras, em especial em India Song (1973/1975) e Césarée (1979).

\section{Não ver para não perder}

O primeiro aspecto a ser analisado é o tratamento dado por Resnais e Duras ao tema de Hiroshima. O nome da cidade japonesa destruída pela bomba atômica, símbolo maior do horror como produto humano, colocava questões éticas incontornáveis. A temporalidade deste acontecimento é destacada em uma fala do filme: "Duzentos mil mortos./ Oitenta mil feridos./ Em nove segundos. Essas cifras são oficiais"1 (DURAS, 1960, p. 33). O tempo foi abolido, trata-se de um instante que mudou dramaticamente o significado da presença humana na Terra, em toda a sua extensão temporal; o ínfimo toca o imensurável. Nisso, Hiroshima difere

\footnotetext{
1 «Deux cent mille morts./ Quatre-vingt mille blessés./ En neuf secondes. Ces chiffres sont officiels». Observação: todas as traduções não indicadas são de minha autoria.
} 
radicalmente até mesmo da morte industrial nos campos de concentração nazistas. Este sentido, no entanto, é apenas sugerido no filme, não é objeto de debate ou análise.

Algumas decisões de Resnais e Duras são expostas na sinopse, tal como publicada em livro (DURAS, 1960). Ambos compartilhavam a certeza de que não valia a pena fazer "mais um filme" sobre Hiroshima. Os muitos já produzidos até então, como reconstituições e reportagens, são mencionados pela atriz francesa ao longo da sequência inicial do filme, fundamentando sua afirmação de ter visto "tudo em Hiroshima", à qual o arquiteto japonês contrapõe a fala de que ela "não viu nada em Hiroshima". Mesmo tendo visto tudo o que havia para ver, este tudo equivale a nada, segundo a posição marcada por ele. Os autores do filme assumem, também, o partido ético de não "representar o horror pelo horror", não provocar a sensibilidade com uma imagem que substitua as inexistentes e irreproduzíveis imagens do próprio horror de Hiroshima.

Essas decisões e suas consequências poéticas definem uma lógica: aceitar que se possa ver qualquer coisa em Hiroshima equivale a admitir que seja possível compreender Hiroshima. A bomba atômica deixaria o seu lugar limite, que toca o absoluto do horror, o abismo rasgado entre um antes e um depois na história da humanidade, para ser mais uma bomba, sem dúvida a mais poderosa e destruidora, mas ainda assim uma unidade em uma categoria. Ao não a submeter a um discurso que possa tornar familiar sua violência, Hiroshima seria, talvez, preservada. Simbolizar, compreender Hiroshima, seja como for, é falsificá-la; significá-la com o intuito de lembrá-la é o modo mais certo de esquecê-la.

Segundo essa lógica, compreende-se que a francesa vê as imagens como capazes de informar e de significar o que mostram: ver tudo - os filmes, os lugares, os museus - seria um modo de participar da experiência de Hiroshima. $\mathrm{O}$ japonês, por seu turno, vê as imagens como simulacros que se interpõem à irrecuperável experiência, inúteis para transpor a linha do incognoscível postulado pelo nome Hiroshima. Ao guardar e contrapor as duas posições, Resnais e Duras afirmam a dúvida, o relançar constante da questão quanto ao que significa ver ou não ver, sem deixar que a resposta se estabilize em qualquer dos polos.

Neste processo, dois elementos se afirmam: o nome e o lugar. Primeiramente, o nome do lugar, mas este se tornará o nome da personagem, conforme apontado. Assim, partindo da recusa do discurso sobre Hiroshima, o filme conta a história de um encontro amoroso, em toda a sua banalidade, porém situado em um lugar que o desloca: "Esse encontro, tão banal, tão cotidiano, tem lugar na cidade do mundo onde ele é mais difícil de se imaginar: HIROSHIMA"2 (DURAS, 1960, p. 11). No interior dessa história, surge uma outra história que será identificada com o nome de

\footnotetext{
2 "Cette étreinte, si banale, si quotidienne, a lieu dans la ville du monde où elle est le plus difficile à imaginer: HIROSHIMA.»
} 
Nevers. Retomo-a para seguir com a análise: no momento da Liberação da França, quando vai ao encontro de sua namorada francesa, o oficial alemão é alvejado por uma bala anônima e morre, sob o corpo dela. A comunidade de Nevers trata-a como uma pária, humilha-a, raspa sua cabeça. A jovem enlouquece e é confinada no porão de sua casa durante meses, até que um dia, no exato momento em que a guerra termina, é acometida de lucidez, sua mãe deixa que ela vá até Paris. Lá, mistura-se com a alegria das ruas, enquanto as manchetes dos jornais estampam a palavra Hiroshima.

Importante realçar que as "tondues ", mulheres que tiveram suas cabeças raspadas por terem tido algum tipo de relacionamento com alemães durante a Ocupação, são uma realidade histórica. Seu documento mais famoso é a fotografia de Robert Capa intitulada «La tondue de Chartres», que retrata uma mulher de cabeça raspada, com um bebê no colo, conduzida por um soldado e acompanhada com interesse por uma multidão sorridente. As mulheres eram julgadas e condenadas sumariamente por essas espécies de tribunais populares, insultadas como "putas da nação", suas cabeças eram raspadas e o desenho da suástica nazista era feito em suas testas; depois eram reunidas e levadas a circular, a pé ou na caçamba de um caminhão, expostas ao público.

Há uma mistura entre o âmbito político nacional e o âmbito eróticoafetivo de um corpo. O amor com o soldado alemão é percebido como um estupro e um adultério contra a nação; o corpo de uma francesa é considerado, naturalmente, como parte do território francês, reservado, pois, a corpos franceses. Entregar-se a um inimigo é permitir-se violar e, ao mesmo tempo, trair os seus potenciais ocupantes legítimos, o que faz da jovem francesa duplamente culpada. Isso justifica a barbárie, como se, no linchamento, a comunidade assumisse um autoproclamado mandato público.

Se um país ou uma nação podem ser entendidos como abstrações jurídico-ideológicas, o exercício do poder em seu nome é muito concreto. A violência praticada pela comunidade de Nevers contra a jovem revela um corpo integrado a um território e demarcado pelo exercício desse poder mesmo. Com Foucault, compreende-se o poder não apenas como regulação jurídica ou estruturas institucionalizadas, mas sobretudo, em qualquer âmbito em que seja circunscrito, como um exercício estratégico e tático, que estabelece pontos de apoio, vetores de ação e resistência, e se mostra em sua positividade radical (cf. FOUCAULT, 1976, p. 121 e seguintes). Em Hiroshima mon amour - e outras obras de Marguerite Duras -, a narrativa situa-se no ponto em que o corpo e o mundo - potência e poder - colidem e se interpenetram, em uma forma peculiar de biopoder. Hiroshima ecoa esse enredo trágico, muito tempo depois, a reavivá-lo em um lugar não de esquecimento, mas de dormência. A mulher o resgata em seu corpo, a partir do encontro com o amante japonês, que representa para ela uma abertura para si mesma. 
A visão de Duras em relação a como as histórias de Nevers e de Hiroshima se justapõem em Hiroshima mon amour está explicitada na sinopse do roteiro do filme: "É como se o desastre de uma mulher [humilhada] em NEVERS e o desastre de HIROSHIMA se correspondessem EXATAMENTE"3 (DURAS, 1960, p. 17, grifos no original). Num número dos Cahiers du Cinéma organizado e escrito por Duras (Les yeux verts, 1980), a autora afirma: "coloquei diante da cifra enorme dos mortos de Hiroshima a história da morte de um único amor inventado por mim"4 (DURAS, 1996 [1980], p. 34).

Duras coloca, ao lado da grande história política, uma história em alguma medida correlata, conclamando o espectador a acessar a sua memória da dor com maior proximidade. Com isso, Duras cria algo como uma dramaticidade lírica, enunciando a palavra ao rés-do-corpo, no lugar da dor e do ininteligível, o que para ela é a condição mesma para pensar, escrever.

Ambas histórias de desastres, uma ficcional (inspirada em fatos históricos) que é contada, outra real que é calada, são como que absorvidas pelo nome próprio do lugar onde foram vividas, e esse nome servirá para nomear a personagem. Isso é válido sobretudo para Nevers - a Hiroshima que nomeia o japonês é menos a da catástrofe que a do amor vivido no tempo filme, sem, contudo, alijar do nome Hiroshima o seu significado universal.

\section{O nome próprio}

O nome próprio, em Hiroshima mon amour, designa um lugar que, interpenetrado com a personagem por uma história de amor e ruptura violenta, passa a nomeá-la também. Percebe-se que o nome próprio pode tornar-se um símbolo carregado de intencionalidade. Ele é feito, no entanto, de um caráter indicial do qual não pode liberar-se. John Stuart Mill já afirmava que um nome próprio (proper name) é "uma palavra que responde ao propósito de mostrar de que coisa estamos falando, mas sem contar nada sobre ela"5 (STUART MILL, 2009 [1843], p. 47). Como "referência de um significante puro a um existente singular", Jacques Derrida afirma que o nome próprio é "a esse título intraduzível" 6 (DERRIDA, 1985, p. 210). Essa intraduzibilidade diz de seu caráter insubstituível, sendo ele próprio um substituto no discurso desse existente

\footnotetext{
3 "C'est comme si le désastre d'une femme tondue à NEVERS et le désastre de HIROSHIMA se répondaient EXACTEMENT ». Observação: «femme tondue » é a mulher que teve a cabeça raspada, traduzi por "humilhada" para explicitar o sentido que a palavra conota no trecho destacado.

${ }^{4}$ " j'ai mis face au chiffre énorme des morts d'Hiroshima l'histoire de la mort d'un seul amour inventé par moi.»

5 " $a$ word which answers the purpose of showing what thing it is we are talking about, but not of telling anything about it."

${ }^{6}$ "la référence d'un signifiant pur à un existant singulier - et à ce titre intraduisible. "
} 
singular, que o ancora em uma corporalidade situada. Mobiliza-se o devircoisa da palavra.

Um texto feito apenas de nomes próprios equivaleria à memória de Funes, o personagem de Jorge Luis Borges que se lembra de tudo e de cada coisa em sua singularidade absoluta, por ser incapaz de esquecer. Há uma passagem do conto de Borges em que o nome próprio vem substituir até mesmo os termos mais abstratos, quando Funes postula "um sistema original de numeração".

Não o tinha escrito, porque o pensado uma única vez já não se
lhe podia apagar. Seu primeiro estímulo, acredito, foi o
desagrado de que os trinta e três orientais requereram dois
signos e três palavras em vez de uma única palavra e um único
signo. Aplicou depois esse disparatado princípio aos demais
números. Em lugar de sete mil e treze, dizia (por exemplo)
Máximo Pérez; em lugar de sete mil e catorze, A Ferrovia; outros
números eram Luis Melián Lafinur, Olimar, enxofre, os bastos, a
baleia, o gás, a caldeira, Napoleão, Agustín de Vedia. Em lugar de
quinhentos, dizia nove. (BORGES, 1998, p. 544)

Desnecessário dizer que as operações matemáticas são impossíveis nesse sistema, embora seja possível, feita a operação de outro modo, nomear cada resultado e cada operação com um nome próprio. ${ }^{7}$ Para haver pensamento é preciso categorizar, esquecer diferenças, transcender cada coisa para produzir um logos. Levado ao limite, o devir-coisa implode o signo e a linguagem, a possibilidade de um discurso fundado não em absolutos, mas em relações.

O nome próprio, em contraposição, resiste à sua integração na linguagem, é uma incrustação no tecido do discurso. Por isso, afirma Derrida, se "não é possível mais se entender quando só há nomes próprios, não é possível mais se entender quando já não há nomes próprios" (DERRIDA, 1985, p. 211). ${ }^{8}$ Entre tantos substantivos comuns, o nome próprio finca no território metaforizante do mundo a bandeira da literalidade, da tautologia, que dá lastro a todo o restante. Duras baterá o passo nesta tautologia, de modo que o nomear para ela será sempre ritualizado, enquadrado, repetido, dissociado de outras funções. Não se nomeia para, nomeia-se como quem reconhece uma existência em seu todo e lhe dá presença.

Diferentemente de Funes, Marguerite Duras seleciona e restringe os nomes próprios em torno dos quais imanta seu mundo, e lança no anônimo comum os demais existentes. Se a Hiroshima da bomba é preservada pela

\footnotetext{
7 Borges imagina outras formas de totalidade vertiginosa e paralisante, como na "Biblioteca de Babel" (BORGES, 1998, p.516-23) ou nessa anotação atribuída a Suárez Miranda, "Do rigor na ciência", parte do livro O fazedor (BORGES, 1999, p. 247).

8 «Et on ne peut s'entendre quand il n'y a que du nome propre, et on ne peut plus s'entendre quand il n'y a plus de nom propre.»
} 
dúvida, Nevers é relembrada, contada, revivida no filme, e lançada em um processo em que arrisca perder-se: a consumação do luto que apagará a tragédia para que siga a vida. Há o momento no filme em que a entrega de sua história de amor ao esquecimento mostra-se à francesa com evidência e não sem o despontar do desespero. Sua voz enuncia: "Enquanto isso meu corpo se incendeia já de sua lembrança. Eu queria rever Nevers... o [rio] Loire." 9 (DURAS, 1960, p. 118). Esta é a chave para que, em uma espécie de recitativo, cujo ritmo lembra as falas do início do filme, ela enuncie o esquecimento que já penetra de maneira irrefreável a sua memória: "História de três vinténs, eu te entrego ao esquecimento"10 (Idem, ib. p. 118). Sua fala prossegue com sentenças nominais, apresentando essa menina de Nevers como uma imagem que se separa dela e se distancia:

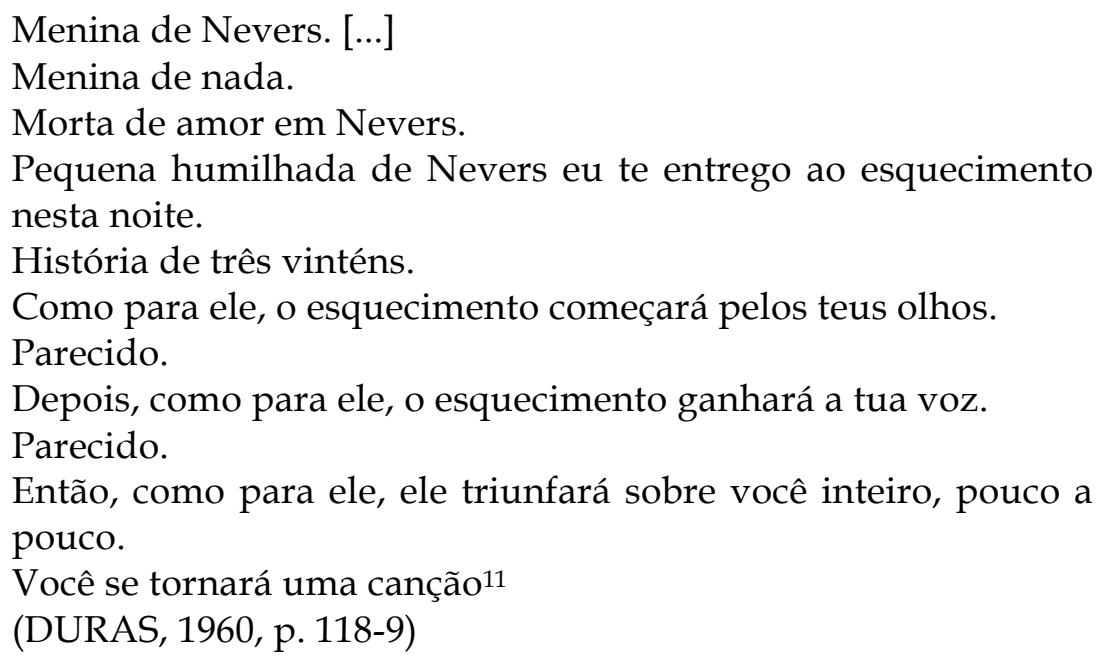

Note-se, no penúltimo verso, o deslizar de uma mudança de gênero da pessoa interpelada: "você inteiro" (toi tout entier). Se a fala era dirigida à menina que ela mesma fora em Nevers, ao final (e crivelmente desde a primeira vez que se enuncia "como para ele..."), pode-se aventar que agora o interpelado é seu amante japonês, já que ela inicia aqui uma espécie de luta para lançá-lo, ele também, no esquecimento.

A esta cena de intenso lirismo, reveladora da tomada de consciência da perda de uma dor que lhe era tão cara, e anúncio da dor de uma nova perda que apenas se inicia, segue-se uma cena fortemente contrastante. A francesa vai a um bar e é abordada por um outro homem, japonês como o seu amante, que procura iniciar uma conversa, em inglês. $O$ estranhamento, alheamento de si, é total. Isso permite interromper o movimento catártico que começa a acumular pressão, para que o

\footnotetext{
9 "Tandis que mon corps s'incendie déjà à ton souvenir. Je voudrais revoir Nevers... la Loire. »

10 «Histoire de quatre sous, je te donne à l'oubli.»

11 «Petite fille de Nevers. [...]/ Petite fille de rien./ Morte d'amour à Nevers./ Petite tondue de Nevers je te donne à l'oublie ce soir./ Histoire de quatre sous./ Comme pour lui, l'oubli commencera par tes yeux./ Pareil./ Puis, comme pour lui, l'oubli gagnera ta voix./ Pareil./ Puis, comme pour lui, il triomphera de toi tout entier, peu à peu./ Tu deviendras une chanson. »
} 
espectador chegue à cena final emocionalmente preservado. Quando o japonês chega ao quarto do hotel dela pela última vez, ela grita e o agride: "Eu vou te esquecer, eu já te esqueço. Olhe para mim como estou te esquecendo! Olhe para mim!"12 (DURAS, 1960, p. 124). A essa nova ruptura - que era anunciada, pois ambos sabiam que em poucas horas ela iria embora de Hiroshima, provavelmente para sempre -, ela tenta opor uma recusa.

Esta cena, como sabemos, concluir-se-á com a nomeação mútua dos amantes. Duras descreve o estado em que a francesa se encontra nesse momento como um "maravilhamento" (émerveillement) e diz que "ela conseguiu submergi-lo (le noyer) no esquecimento universal. Ela está por isso maravilhada"13 (DURAS, 1960, p. 124). Olham-se sem se ver, para sempre, o olhar intransitivo integra definitivamente o corpo ao lugar, aprisionando-o no amuleto intraduzível de um nome próprio.

Da percepção do esquecimento da história de Nevers, considerando a correspondência que Duras procura estabelecer entre esta história e a do desastre de Hiroshima, tira-se a inevitável reflexão: se é possível perder Nevers, por que não se poderia perder Hiroshima? É aceitável deixar que Hiroshima cicatrize e que homens e mulheres sigam sua existência coletiva alheados dessa dor, da dor de Hiroshima? A recusa do filme em falar de Hiroshima, em mostrar Hiroshima, e mantê-la condensada em um nome próprio, talvez seja a única maneira de preservá-la, para que ressurja, inesperada, no corpo de cada um que a encontre. Sobretudo no momento em que o filme é lançado, em que o esforço de "reconstrução" da paz mundial se faz, como regra, soterrando a dor absoluta de Hiroshima e dos campos de concentração com discursos e mais discursos integradores.

\section{Breve inventário de uma tópica}

Os elementos que encontramos em Hiroshima mon amour reaparecem em diversas obras de Marguerite Duras. A constante durassiana parece ser que, diante do acontecimento que põe em presença a morte e o amor, a personagem vive um arrebatamento (ou maravilhamento) lírico cuja consequência imediata é uma interpenetração entre o lugar e a personagem, a ponto de que um nomeie o outro e vice-versa, tornando-se ambos uma coisa só. Dessa fusão, consolidada pelo nome, restam os rastros a serem resgatados, aos cacos, sem nunca recuperar uma narrativa total, pois esta já seria sedimentação, cinzas de um poder abafador, mascarador; no contato com esses rastros, se não houver resistência que se interponha, a reprodução do arrebatamento poderá ter lugar. São muitos os avatares dessa tópica na obra de Duras, e talvez a primeira vez que ela surja com todos os seus elementos presentes e conjugados seja em Hiroshima mon

\footnotetext{
12 «Je t'oublierai! Je t'oublie déjà! Regarde, comme je t'oublie! Regarde-moi! »

13 «Elle a réussi à le noyer dans l'oubli universel. Elle en est émerveillée.»
} 
amour, em especial na história de Nevers, resgatada no corpo da personagem, renomeada com o nome do lugar.

Duras formula o corpo desejante imediatamente político, buscando uma correspondência entre os afetos do corpo e as afecções do mundo. É assim que o mundo político se cartografa a partir do corpo, dado que é no corpo que os processos políticos adquirem sentido e memória, só a partir do corpo pode se formar uma perspectiva global. Essa forma de universalidade transborda para além do histórico, adentrando o campo do arquetípico, do sagrado. Há, portanto, uma contraposição radical de duas escalas, para além da oposição local-global postulada pela geopolítica; Duras reduz o local ao corpo - no que se poderia chamar de dimensão lírica - e amplia o global para além do mensurável - em uma dimensão épica; não raro, essas dimensões, um quase nada e uma imagem da totalidade, como que se igualam por uma abolição do tempo e do espaço, resultado de uma hiperestesia, de um corpo por isso hiperextenso.

Esta tópica já se encontra, ainda que incompleta, em seu primeiro grande romance, Un barrage contre le Pacifique (1950). A barragem é um construto do corpo, em última instância, é uma metonímia do corpo da mãe que se expõe tragicamente à corrupção dos agentes da administração colonial; o oceano Pacífico, que integra e amplia o mar da China, é ao mesmo tempo a sua imagem concreta e a metáfora hiperbólica das devastadoras forças opressoras que arrasam a utopia da mãe. Como motor desse confronto, há o engajamento onipotente da mãe, que se acredita capaz de vencer o oceano, com tal paixão que chega a convencer a população local a construir a barragem; seu fracasso cabal é o gatilho para sua loucura. O mar (outra constante na obra durassiana) já aparecia com importância (e ligado à morte) num romance anterior (La vie tranquille, 1944). Os quatro romances que Duras lança nos anos 1950, antes de chegar a Hiroshima, todos acontecem à beira-mar, no caso, o Mediterrâneo, e três deles têm um topônimo no título. Le marin de Gibraltar reúne novamente os elementos dessa tópica em formação, só que recombinados: o marinheiro e Gibraltar constituem uma espécie de não-corpo em um não-lugar, pois são objetos da constante busca de um reencontro, que ocorre ciclicamente, mas de modos imprevisíveis; objeto do amor da mulher em seu iate, o marinheiro é um criminoso foragido; o livro se passa nessa flutuação e vai se abrindo cada vez mais a um imaginário desterrado.

O romance Moderato Cantabile (1958) constrói-se a partir do retorno cíclico ao local onde acontece um crime logo no início: um homem atira à queima-roupa em sua amante e deita-se sobre ela, de modo que ela expira sob seu corpo; a cena é bastante próxima da morte de Nevers, com elementos deslocados, como a origem do tiro fatal e o fato de que quem morre em Moderato é a mulher. A incompreensão e o fascínio em torno dessa cena levam Anne Desbaresdes a voltar ao mesmo lugar, dia após dia, onde passa a encontrar um homem com quem viverá uma espécie de 
adultério; diversos são os elementos em comum com o encontro amoroso de Hiroshima.

Já em Le ravissement de Lol $V$. Stein encena-se a ruptura do amor como um arrebatamento (em seu duplo sentido, como maravilhamento / deslumbramento e como rapto), em que o noivo de Lol é levado, na noite do baile de S. Thala, pela mulher vestida de negro; Lol enlouquece e, mesmo depois de até certo ponto recuperada, continua ligada ao lugar e ao nome de $S$. Thala, para o qual ela retorna ciclicamente, seja por ir mesmo até este lugar, seja por reencontrá-lo em outros espaços através das marcas no corpo.

A obra de Duras se mostra, então, como uma rede interconectada e situada, uma cartografia afetivo-política. Percorrer seus escritos e sua produção audiovisual é peregrinar por uma rede de lugares marcados pelo amor intenso e pela ruptura violenta, cujas relíquias - marcas de corpos amorosos situados na geografia - reacendem um processo de conexão, a um só tempo, consigo e com o mundo. Cabe aqui resgatar duas falas de Duras que se ligam neste contexto. A primeira, escrita em 1980, diz respeito ao senso político e sua eventual perda:
A perda política
Para muitas pessoas, a verdadeira perda do senso político está em juntar-se à formação de um partido, submeter-se à sua regra, sua lei. Muitas pessoas, também, quando falam em apolitismo, falam antes de tudo de uma perda ou de uma falta ideológica. Eu não sei quanto a vocês, o que vocês pensam. Para mim, a perda política é antes de tudo a perda de si, a perda da cólera tanto quanto a da doçura, a perda da raiva, da faculdade de sentir raiva, tanto quanto a faculdade de amar, perda da imprudência tanto quanto a da moderação, a perda do excesso tanto quanto a da contenção, a perda da loucura, da ingenuidade, a perda da coragem tanto quanto a da covardia. A perda do espanto diante de todas coisas tanto quanto a da confiança, a perda do pranto assim como a da alegria. É isso o que eu penso. ${ }^{14}$ (DURAS, 1996 [1980], p. 13)

Todo o discurso de Duras sobre a questão política passa diretamente pelo corpo, pela verdade do corpo, sua capacidade de afetar-se e afetar o mundo, o contrário de uma indiferença ou mesmo da racionalização. É no contato direto com a riqueza de possíveis do corpo que Duras encontra a

\footnotetext{
14 «La perte politique./ Pour beaucoup de gens la véritable perte du sens politique c'est de rejoindre une formation de parti, subir sa règle, sa loi. Pour beaucoup de gens aussi quand ils parlent d'apolitisme, ils parlent avant tout d'une perte ou d'un manque idéologique. Je ne sais pas pour vous ce que vous pensez. Pour moi la perte politique c'est avant tout la perte de soi, la perte de sa colère autant que celle de sa douceur, la perte de sa haine, de sa faculté de haine autant que celle de sa faculté d'aimer, la perte de son imprudence autant que celle de sa modération, la perte d'un excès autant que la perte d'une mesure, la perte de la folie, de sa naïveté, la perte de son courage comme celle de sa lâcheté, que celle de son épouvante devant toute chose autant que celle de sa confiance, la perte de ses pleurs comme celle de sa joie. C'est ce que je pense moi. » (DURAS, 1996 [1980], p. 13).
} 
política, um campo onde se constrói o comum. Suas descrições de Maio de 1968, por exemplo, são de que o amor corria solto pelas ruas, sem direção nem controle de qualquer instituição de poder (cf. VIRCONDELET, 1972). A correspondência com a loucura é conscientemente buscada pela autora, que assume a figura do louco como um arquétipo (a despeito de sua condição patológica), como aquele que é vazio, destituído das resistências culturais, intelectuais, e, portanto, poroso, apto a ser perpassado pelo mundo e pelos outros (cf. DURAS; PORTE, 1977, p. 96). É em meio a uma descrição sobre a loucura que Duras, a partir de seu modo pessoal de viver a presença nos espaços, formula a possibilidade de uma escuta da memória do lugar:

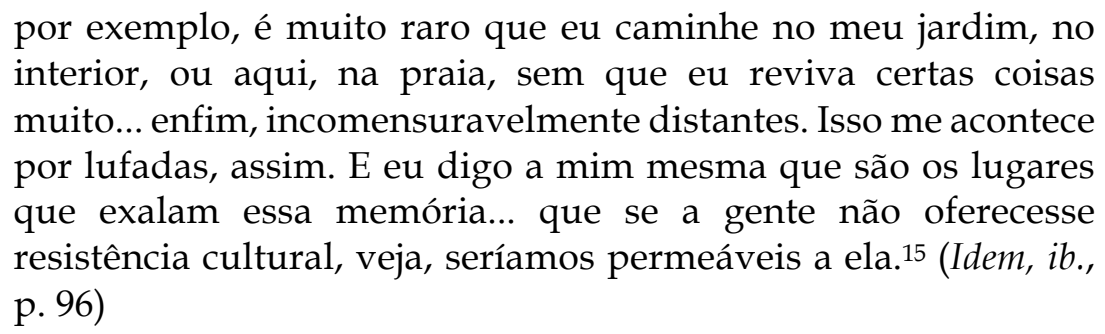

Nessa configuração, a política - entendida como um processo vital e imediato, a um só tempo pessoal e coletivo, afetivo e ético - arrisca perderse na medida em que o vivido se vê intermediado por um discurso de razão que venha sobrepor-se ao contato com o vivido ou o que restou dele nos lugares. Resfriado o corpo potente do amor, vêm instalar-se as cinzas do poder, sua sedimentação discursiva em que se cristaliza uma imagem de verdade. Em Hiroshima, na imbricação de memória e esquecimento, é possível que o jogo de representação venha operar uma substituição e, assim, ao mesmo tempo que o corpo sana suas cicatrizes, perde contato com o vivido, permitindo que o esquecimento se infiltre e se propague. A simbolização da morte e o próprio trabalho do luto mostra-se como esquecimento, a possibilidade de seguir vivendo na mesma medida em que se banaliza e dispersa a catástrofe.

Talvez em vão, mas certamente de modo apaixonado, Duras insurge-se contra esse processo e procura ouvir, entre as ruínas do lugar, os rastros do vivido, vozes de corpos amorosos já desaparecidos, sem preencher os silêncios que perpassam os escombros de tempos idos. Procura reencontrar em seu corpo a vibração dos corpos que viveram intensamente no lugar, fazendo do corpo uma força contraideológica, voz mais que discurso, grito pré-pós-palavra.

\footnotetext{
15 "[...] par exemple, c'est très rare que je me promène dans mon jardin, à la campagne, ou ici, sur la plage, sans que je revive certaines choses très, enfin, incommensurablement lointaines. Ça m'arrive par bouffées comme ça. Et je me dis que ce sont les lieux qui la recèlent, cette mémoire... que si on n'offrait pas de résistance culturelle ou sociale, voyez, on y serait perméable. »
} 
Vimos alguns exemplos de como os aspectos constitutivos dessa tópica aparecem em diversas obras de Marguerite Duras. Porém, dentre seus livros, peças de teatro e filmes, a obra que melhor ilustra esse processo é, provavelmente, India Song (livro de 1973, filme de 1975), sendo ela mesma a reescrita do romance Le vice-consul (1966) e que teve no cinema uma versão anterior em La femme du Gange (1973) e um desdobramento em Son nom de Venise dans Calcutta désert (1977). Apenas atentando aos títulos, encontramos os topônimos Índia, [rio] Ganges, Veneza e Calcutá... a partir dos textos, acrescentam-se outros lugares de igual importância, como Lahore - a cidade onde o vice-cônsul comete os seus crimes -, Savanakhet, lugar que se supõe ser a origem da figura quase mítica da mendiga louca, e o baile de S. Thala, palco da instauração da loucura de Lol, que liga esse conjunto de obras ao outro romance de Duras, já citado neste artigo. AnneMarie Stretter é a mulher de negro que chega ao baile de S. Thala e leva consigo o noivo de Lol, Michael Richardson, entregando-a à loucura.

Pode-se deste modo resumir o enredo de India Song: o Vice-cônsul atira contra os leprosos nos jardins de Shalimar, em Lahore, e depois contra sua própria imagem nos espelhos da residência consular, atos que causam escândalo em toda a classe colonial europeia na Índia (a "Índia branca"). Mesmo assim, ele é convidado ao baile na Embaixada da França em Calcutá por Anne-Marie Stretter, esposa do embaixador, que o vice-cônsul ama loucamente. No baile, ele a aborda e ela - que, como regra, não diz não a ninguém - o recusa; ele então grita o seu amor, primeiro dentro da Embaixada, depois pelas ruas de Calcutá deserta. Antes deste desfecho, há uma tentativa de acomodar as coisas propondo ao Vice-cônsul "esquecer Lahore", ao que ele responderá que "as pessoas me separam de Lahore, eu não me separo" e, finalmente: "Lahore sou eu". ${ }^{16}$ Todos esses amores exacerbados, cujas rupturas ou bloqueios são vividos em plenitude, marcam intensivamente os lugares, que passam a aderir aos nomes dos personagens.

Adiciona-se uma outra camada. Esses amores são vividos no interior do horror, figurado por uma Índia imaginária, que vem criar o cenário de um mundo em deterioração. Este mundo se mostra por contraste: o luxuoso baile da Embaixada protegido do exterior apenas por grades, e a Índia em volta, marcada pela lepra, a fome e a miséria, os dois perpassados por um calor insuportável e os sons que atravessam de um lado ao outro. Apenas o Vice-cônsul, com seus tiros, e Anne-Marie, que oferece as sobras de seus banquetes aos mendigos, dirigem-se ao mundo exterior e são por ele afetados, porque vivem na pele o desespero, a impossibilidade cotidiana das Índias, sendo, pois, personagens preservados em sua dimensão política.

\footnotetext{
16 «Lahore, c'est moi », repetindo a fórmula de Luís XIV, «L'État, c'est moi », e de Gustave Flaubert: "Madame Bovary, c'est moi ».
} 
O restante da classe colonial procura abafar o exterior assimilandoo num discurso generalista. No entanto, o diálogo a seguir revela entre o interior e o exterior da Índia branca uma estranha conexão (DURAS, 1973, p. 90-1):

- Você reparou? Os brancos aqui só falam de si mesmos. O resto... E no entanto... os suicídios de europeus aumentam com as fomes...

-...fomes que eles não sofrem... (Risinho.)

- É.17

O corpo extrapola as cinzas discursivas que o soterram. Em India Song, essas histórias são resgatadas sob a forma de fragmentos, ou "cacos de memória" (" débris de mémoire »), passados por uma multiplicidade de memórias (as Vozes, que observam e comentam as cenas, relembrando fragmentos da história), e o filme se constrói também a partir de imagens incompletas. Encena-se, em meio a isso, não propriamente uma narrativa, mas o acúmulo intensivo de energia erótico-política que só se dissipa, em parte, com a explosão dos gritos do Vice-cônsul (cf. AYER, 2020). Son nom de Venise dans Calcutta désert radicaliza ainda mais este processo e faz a banda sonora completa de India Song soar sobre um novo filme de imagens. Qual filme? Duras retorna às locações onde filmou India Song e as documenta tal como as reencontra agora, arruinadas, com paredes rachadas e pórticos caídos, o mato a crescer por toda parte, e os espelhos, tão importantes no primeiro filme, estilhaçados pelo chão. É como se o filme das vozes, dos sons, da música, fosse agora a memória do lugar - memória de amor, morte, ruptura e loucura - a ressoar ali, em meio às suas ruínas, e isto fosse assumido como a própria poética do filme.

Feito este comentário sobre India Song (e obras conectadas), é preciso dizer que seria possível reencontrar esta tópica, ainda que parcialmente, em quase toda a obra de Duras, como vimos acima, por meio de alguns exemplos. Para finalizar, gostaria de analisar uma obra que se situa já na fase final da produção fílmica de Duras: Césarée, curta-metragem realizado em 1979.

\section{Césarée}

Césarée coloca no centro do discurso literário e fílmico a fusão da personagem com o lugar - lugar do amor violentamente rompido - e o caráter arquetípico, atemporal, sagrado, dessa fusão. $O$ filme se inicia com a voz da própria Marguerite Duras a enunciar: “Césarée. Césaréa. O lugar 17 « - Vous avez remarqué? Les Blancs ici ne parlent que d'eux-mêmes. Le reste... Et pourtant... les suicides
d'Européens augmentent avec les famines...// - ...dont ils ne souffrent pas... (Rire léger.) // - Non... » 
se chama assim. Césarée. Césaréa"18 (DURAS, 1979, transcrito a partir do filme). Pouco depois, ela diz: "Só resta a memória da história e apenas essa palavra para nomeá-la: Césarée. A totalidade. Nada além do lugar e da palavra" (DURAS, 1979). Simultaneamente, há o violino solo de Amy Flamer e, como imagem, um travelling a circundar a escultura, que representa o corpo nu de uma mulher sentada com uma das mãos na cabeça, mostrando-a de todos os ângulos, como a apresentar uma personagem. Veremos logo que Césarée é também o nome da personagem, a rainha judia que se deixa sequestrar pelo César, é levada cativa para Roma, mas finalmente é recusada pelo Senado romano. Trata-se de uma retomada da tragédia Bérénice, de Racine, como revelou Duras em uma entrevista (cf. DURAS, 2001 [1984], p. 170). Duras enfatiza que a rainha judia fora recusada "por razões de Estado". Em certa medida, como em Nevers, é uma mulher que será condenada à exclusão e à humilhação por um coletivo que interdita o amor em nome de um conceito ligado à nação, que se sobrepõe aos corpos. O César obedece ao Senado, degrada-se como homem à reles condição de imperador, mas o gesto de Césarée, que Duras considera particularmente comovente, é o de deixar-se escravizar, tendo sido rainha, por amor.

A tópica de que estamos tratando aqui está, portanto, colocada nos elementos-chave da narrativa; entretanto, terá desdobramentos ou correspondências em outros aspectos constitutivos da obra, por exemplo, a relação entre as imagens e a fala no filme, e como se resgata a relação com o lugar e seus rastros. Revisto em perspectiva em relação a Hiroshima mon amour, percebe-se como esse jogo se tornou conceitualmente mais sutil, pois agora o encontro com o lugar se dá por uma sobreposição ou desdobramento da imagem imaginária sobre a imagem documental.

Retomando a cena inicial, a escultura enfocada é uma das muitas de Aristide Maillol (1861-1944) que têm como tema o corpo feminino e que povoam o jardim das Tuilerias, em Paris, tendo o palácio /museu do Louvre ao fundo. Desde logo, uma sobreposição: o lugar e a escultura são amplamente conhecidos, mas ambos são renomeados, reapresentados com um nome de mulher, que primeiro nomeia a personagem para, ato contínuo, nomear o lugar. Ou melhor, «Césarée » é já a marca do amor da rainha, que assume como nome o título imperial de seu amante, e este nome transbordará para o lugar. A imagem que vem em seguida é de outra escultura, em pedra, que representa uma rainha coroada e que está circundada pelas barras metálicas da estrutura de um andaime - usado certamente em trabalhos de restauração -, figurando uma rainha cativa (Figura 1). As linhas dos andaimes apenas sugerem as grades de uma prisão, sem, no entanto, se fechar, de maneira que caberá ao espectador compreender essa sugestão e completá-la. Trata-se, pois, de usar uma

\footnotetext{
${ }^{18}$ Em português, a cidade israelense se chama Cesareia; na tradução, mantive em francês, para que não se perca a modulação sonora empreendida por Duras.
} 
imagem documental para provocar o trabalho de imaginação do espectador, como se o filme ao qual assistimos fosse de algum modo como o texto de um livro: não as imagens definitivas, acabadas, ao invés disso, só a sugestão para que a figuração imaginária seja um trabalho de cada um de nós. Diversas serão essas sugestões, que costuram a imagem vista com a imagem imaginada, que se desdobra delas a partir do trabalho que operam por meio da voz as palavras recitadas. A voz menciona a areia branca do mármore, alegoria do tempo, e simultaneamente vemos a lona que protege a estátua e seus andaimes encardida de um pó branco. Mais adiante, quando se refere ao mar, o travelling é produzido de dentro de uma embarcação que percorre o rio Sena e filma suas águas e uma de suas margens. São muitas as costuras como essas, que ecoam a história contada na imagem, como rastros da ficção na imagem documental.

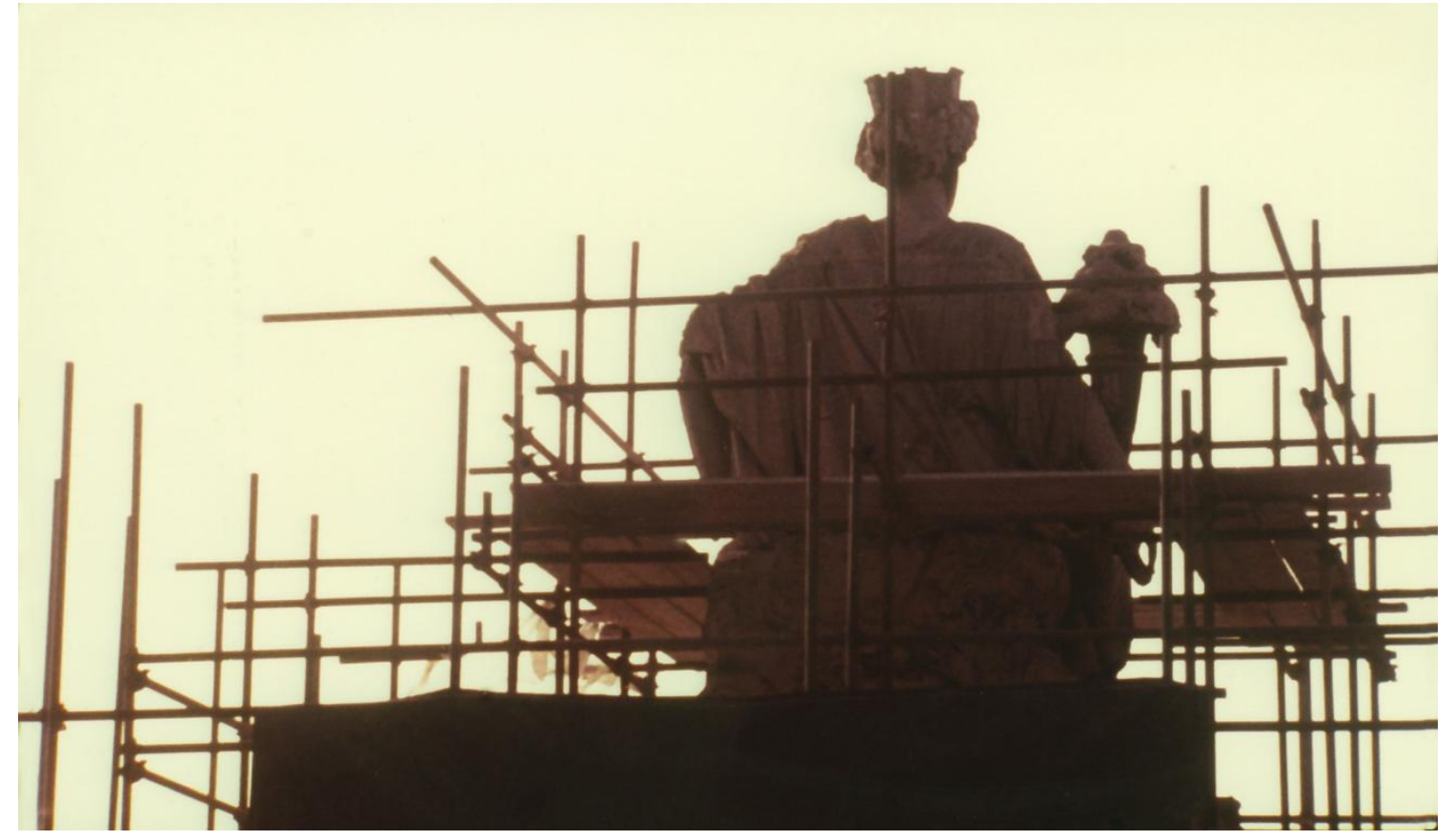

Figura 1: A rainha cativa em "Césarée ». Fotografia de Jean Mascolo, 1979; reprodução cedida pelo seu autor.

Assim, o lugar marcado pelo amor e por sua ruptura, a paisagem de Césarée e os rastros desse amor são reencontrados em Paris, em imagens que mais sugerem do que mostram, e que, inseminadas de imaginário pelas palavras enunciadas no áudio, poderão se transformar num filme sobre o filme. É neste contexto que outras esculturas de Maillol surgem, em tomadas estáticas ou em travellings; algumas dessas esculturas sugerem por si mesmas o movimento, como se o corpo reconstruído em bronze estivesse caído ou lançado em um fluxo de águas correntes. Em ressonância com a história contada aos fragmentos, essas esculturas parecem figurar o corpo da heroína capturado no momento mesmo em que 
vive o desespero pela interdição do amor. As esculturas tornam-se as próprias máscaras da tragédia.

Texto e imagem partem de um corpo, que ganha um lugar inserido em uma história. Aos 7 min42s, o texto recitado vai situar o lugar em relação a outros lugares, primeiro próximos - o caravançarai, o lago - depois mais amplos - os campos de banana e de milho, os laranjais - e finalmente mais distantes, referências globais: "Ao sul, Jerusalém; na direção do oriente, a Ásia, os desertos". Jerusalém é uma cidade relativamente próxima, mas como referência geográfica é planetária. Ao mencionar a Ásia, extrapola-se qualquer referência espacial mensurável a partir do corpo para situar o lugar relativamente ao globo terrestre; finalmente, com "os desertos", desliza-se sutilmente para o universo mítico. A fala a seguir retorna ao corpo, à personagem, para agora estabelecer referências temporais: "Ela era muito jovem: 18 anos, 30 anos, 2 mil anos". Como a sequência que levou do lugar geográfico a uma espacialidade totalizante, agora esta sequência perfaz a trajetória que vai da temporalidade do corpo à temporalidade do mito, igualando-as por torná-las indiferentes.

\section{Para concluir: a potência contra o poder}

Marguerite Duras faz de cada gesto autoral um gesto político, o vivido intenso como equivalente da escritura. A identificação entre a personagem e o lugar, constituída por uma história de amor e morte e condensada em um nome próprio perpassa, como vimos, a obra de Marguerite Duras. Provocada a escrever sobre Hiroshima, algo que ela não faria se não fosse por uma encomenda (cf. DURAS, 1996 [1980], p. 34), Duras parece ter encontrado o elemento (geo)político e o da grande história que até então não haviam aparecido com clareza em seus livros. A relação entre o corpo e o mundo é imediata, como se, ao sobrepor /justapor as escalas micro e macro, Duras abolisse a distinção entre elas, e o todo do mundo fosse passível de ser encontrado em cada coisa e a cada segundo (como em Le camion, cf. DURAS, 1977), e a questão da morte na morte de uma mosca (cf. DURAS; PORTE, 1977; DURAS, 1993). De maneira que o corpo se mostra como um lugar, e o lugar, como um corpo dotado de memória, ambos identificados por um nome próprio, que indica o corpolugar e condensa sem contá-las o todo de suas histórias.

Ao longo de sua trajetória, vai então criando uma cartografia do mundo político e subjetivo a um só tempo. O mundo de Duras é feito de histórias, de Nevers ou Césarée, de Saigon, Calcutá ou Yvelinnes, das praias da Indochina ou as da Normandia, num percurso que vai do extremo oriente - diante do mar da China integrado ao oceano Pacífico - ao extremo ocidente - o canal da Mancha integrado ao oceano Atlântico. Entre esses extremos, há um vazio, um continente (quase) desaparecido dos 
escritos de Duras, a América. O continente dos EUA - origem da bomba que não é mencionada em Hiroshima, exceto pela estupefação diante do fato de que se tenha ousado atirar a bomba, e que se tenha conseguido (cf. DURAS, 1960, p. 48) - parece não ter espaço na geopolítica subjetiva de Marguerite Duras. Numa das poucas passagens em que menciona os EUA, em Les yeux verts, Duras fala de um tempo futuro de "quando a farsa terminar". Ela se refere àqueles que querem dominar tudo, submeter os corpos ao jugo, a potência disseminada ao poder concentrado, e a partir deles chega aos EUA:

Quando a farsa terminar veremos o homem fabricado com medo, o homem de cabeça vazia, aquele de Cabul e de Praga. Eles conseguiram. É o homem que tem medo. Mais que na China ele tem medo, mais que na floresta virgem ou sobre o mar agitado. Esse homem é o soldado mais rentável do mundo. Ele está inteiramente à mercê daquele que provoca seu medo.

A gente se pergunta por quê. Por que querer tudo do homem, tudo do mundo? Não vê resposta. Não vê aonde eles querem chegar, o que lhes trará a hegemonia da Europa. Tem-se o sentimento de estar diante de um doente sob calmante. $\mathrm{O}$ calmante, o valium deles, seu largactyl, sendo aqui o continente U.S.A., o medo dos U.S.A. Esse medo é diferente daquele que eles fazem reinar. É aquele de não chegar a reinar sobre o todo do mundo sangrado até a morte, uma Polônia generalizada. Eles têm medo de não provocar medo o bastante (DURAS, 1996 [1980], p. 50-1).

Neste império do medo, cuja fronteira de retaguarda é o império dos EUA, o medo maior é o de não poder matar. E aí surge, paradoxalmente, a dor que em algum plano humaniza, no ápice da desumanização, da submissão a um poder aniquilador:

Mas aqui, diante desse continente oceânico, eles são impotentes em fazer reinar o medo que eles disseminam. E então o medo deles, em sentido inverso ao de ser morto, é o de não poder matar. Eles estão diante dos U.S.A. como a Alemanha hitlerista diante de seu próprio país em 1941. Mas aqui eles não passam de jeito nenhum, não se trata de uma derrota mas de uma impossibilidade geográfica intransponível. Logo, eles estão diante da configuração terrestre de sua dor, de sua única dor, talvez, a de não aniquilar ${ }^{19}$ (DURAS, 1996 [1980], p. 50-1).

\footnotetext{
19 «Lorsque la farce finira on verra l'homme fabriqué avec de la peur, l'homme à la tête vide, celui de Kaboul et de Prague. Ils l'ont obtenu. C'est l'homme qui a peur. Plus qu'en Chine il a peur, plus que dans la forêt vierge ou sur la mer démontée. Cet homme est le soldat le plus rentable du monde. Il est entièrement à la merci de celui qui provoque sa peur.// On se demande pourquoi. Pourquoi vouloir le tout de l'homme, le tout du monde? On ne voit pas. On ne voit pas où ils veulent en venir, ce que leur rapporterait l'hégémonie de l'Europe. On a le sentiment d'être devant un malade sous calmant. Le calmant, leur valium, leur largactyl, étant ici le continent U.S.A., la peur des U.S.A. Cette peur est différente de celle qu'ils font régner. C'est celle de ne pas arriver à régner sur le tout du monde saigné à blanc, une Pologne généralisée.
} 
Esta dor, fundada num vazio niilista que anula o próprio corpo em primeiro lugar, não será capaz de marcar o mundo, apenas tentará, sem jamais conseguir totalmente eliminar as marcas do amor vivido, da potência dos corpos, do pensamento, do escrever. Sobre essa incapacidade dos impérios, pode-se mencionar uma das últimas produções fílmicas de Duras, Dialogue de Rome (1982), que retoma a história de Césarée, mas agora lança um olhar também sobre o problema do império, a partir de um comentário sobre o paradigma dos impérios, Roma:

Eu não creio que Roma pensasse. Ela enunciava seu poder. Era em outros lugares, nas outras regiões que se pensava. Era em outros lugares que o pensamento tinha lugar. Roma devia ser apenas o lugar da guerra e do roubo desse pensamento, aquele onde ele era editado. (DURAS, 1993, p. 92)

Pensar, aqui, é palavra correlata de escrever, esse verbo que ao longo dos anos, e sobretudo a partir de meados dos anos 1960, adquire um sentido intransitivo para Duras, no mesmo passo em que se torna o campo da experiência política por excelência. Um pensamento só seria possível como gesto autoral, como resposta direta ao vivido e não a uma obediência a qualquer regime social de controle. Daí que a geopolítica subjetiva de Duras, o mundo cartografado por sua escritura, seja uma espécie de mundo sociopolítico em negativo, onde a potência dos corpos, deixada sob a sombra, toma o lugar do poder dos impérios e sua luz. As ruínas de Césarée ardem sob as cinzas de Roma.

\section{Referências bibliográficas}

AYER, Maurício. A música do fim do mundo: orquestrações de literatura, teatro e cinema em Marguerite Duras. São Paulo: Elefante, 2020.

AYER, Maurício. "O cinema como ato político". In: KUNTZ, Cristina; AYER, Maurício. Olhares sobre Marguerite Duras. São Paulo: Publisher Brasil, 2014.

BORGES, Jorge Luis. Obras Completas I. Trad. de Carlos Nejar; rev. de trad. de Maria Carolina de Araujo. São Paulo: Globo, 1998.

BORGES, Jorge Luis. Obras Completas II. Trad. de Josely Vianna Baptista. São Paulo: Globo, 1999.

Ils ont peur de ne pas faire assez peur. Mais ici, devant ce continent océanique, ils sont impuissants à faire régner la peur qu'ils répandent. Et là leur peur, en sens inverse d'être tué, c'est de ne pas pouvoir tuer. Ils sont devant les U.S.A. comme l'Allemagne hitlérienne devant leur propre pays en 1941. Mais ici ils ne passent pas $d u$ tout, il ne s'agit pas d'une défaite mais d'une impossibilité géographique infranchissable. Ils sont donc face à la configuration terrestre de leur douleur, leur seule douleur peut-être, celle de ne pas anéantir » (DURAS, 1996 [1980], p. 50-1). 
DENES, Dominique. Marguerite Duras: Écriture et politique. Paris: L'Harmatan, 2005.

DERRIDA, Jacques. « Des tours de Babel ». In: GRAHAM, Joseph (ed.). Difference in translation. Ithaca; Londres: Cornell University Press, 1985, p. $209-48$.

DURAS, Marguerite. « Roma ». Écrire. Paris: Gallimard, 1993 (impr. 2003), p. 85-106.

DURAS, Marguerite. La couleur des mots. Entretiens avec Dominique Noguez. Paris: Benoît Jacob, 2001 (1984).

DURAS, Marguerite. Les yeux verts. Paris: Cahiers du Cinéma, n. 312-313, (jun. 1980) 1996 (Petite bibliothèque des Cahiers du cinema).

DURAS, Marguerite. Césarée, Les mains négatives, Aurélia Steiner (Melbourne), Aurélia Steiner (Vancouver). Quatre films écrits et réalisés par Marguerite Duras. Suivis de "La caverne noire", entretiens avec Dominique Noguez DVD. Paris: Benoît Jacob Vidéo, 1979. Filme Césarée. Disponível em: https://youtu.be/IxvjJCOfxHA, acesso em: 10/3/2020.

DURAS, Marguerite. Le camion suivi d'un entretien avec Michelle Porte. Paris: Minuit, 1977.

DURAS, Marguerite. Hiroshima mon amour. Paris: Gallimard, 1960 (impr. 2001).

DURAS, Marguerite; PORTE, Michelle. Les lieux de Marguerite Duras. Paris: Minuit, 1977.

FOUCAULT, Michel. Histoire de la sexualité I: la volonté de savoir. Paris: Gallimard, 1976.

FOUCAULT, Michel. Microfísica do poder. Org. e trad. de Roberto Machado. Rio de Janeiro: Edições Graal, 1979.

METZ, Christian. A significação no cinema. Trad. de Jean-Claude Bernardet. São Paulo: Perspectiva, 2004.

STUART MILL, John. A system of logic, ratiocinative and inductive. E-Book 27942, Project Gutenberg, 31 January 2009 [1843]. Disponível em: https://www.gutenberg.org/files/27942/27942-pdf.pdf, acesso em: $15 / 3 / 2020$.

VIRCONDELET, Alain (org.). Marguerite Duras ou le temps de détruire. Paris: Seghers, 1972 (Écrivains d'hier et d'aujourd'hui).

Recebido em 26 de maio de 2020

Aprovado em 27 de maio de 2020

Maurício Ayer leciona literatura francesa no Departamento de Letras Modernas da Faculdade de Filosofia, Letras e Ciências Humanas da Universidade de São Paulo, é autor de A música do fim do mundo: orquestrações de literatura, teatro e cinema em Marguerite Duras (crítica, 2020), A cidade além das margens (poesia, 2018), Olhares sobre Marguerite Duras (crítica, 2014), coorganizado com Cristina Kuntz, e de Música nas Montanhas: 40 anos do Festival de Campos do Jordão (reportagem histórica, 2009), com Camila Frésca. Contato: mauayer@gmail.com

ORCiD: http:/ / orcid.org/0000-0002-8814-3377

85 | E N S A I O S : HIROSHIMA MON AMOUR: 60 ANOS 